bundled free with every new Macintosh sold or, for others, costs only $\$ 49$ for four disks and a manual. We are truly excited about Hypercard, not only for its low price, but for its simplicity in use, its ease of creating and programming new stacks, and in tailoring existing stacks to meet local needs.

I wish to thank the Rutgers University Council for the Improvement of Teaching for their general support of this project as well as Sandy Dennis, an engineering student who provided a great deal of programming assistance, and Deanna Nipp, a colleague, who provided much feedback and suggestions concerning the program's content, presentation, and evaluation.

\title{
AACR2 rule interpretations
}

\author{
by William A. Moffett
}

Director of Libraries
Oberlin College

\section{and Alan D. Boyd}

\author{
Senior Cataloger \\ Oberlin College
}

In the early days of 1982 , just prior to the microcomputer's conquest of library technical services, three Oberlin College catalogers (Lois Lindberg, Alan Boyd, and Elaine Druesedow) attended a local course on mainframe computer text editing. Text editing in the pre-micro age was an unnatural act, a real solution in search of a problem for the non-programmer. But such a problem did confront our catalogers in the wake of AACR2 and the Library of Congress' quarterly batches of new rule interpretations. The Oberlin catalogers decided to exercise their new text editing skills in the preparation of a cumulation of LC's rule interpretations.

It was clear to Lois, Alan, and Elaine that such a publication would be of interest to many other catalogers, and the project was begun with the intent of making copies available to other libraries on a cost-recovery basis. The resultant, seemingly monstrously-proportioned, 100-page cumulation was reproduced in an initial, somewhat timorous run of 50 copies in the summer of 1982. Lacking the requisite patience to allow the professional literature's notice and review functions to build our subscription list, Alan sent an announcement and sample pages to the heads of cataloging of some 600 major academic and public libraries. The response was immediate. Oberlin's looseleaf LCRI service had 300 subscriptions by the time the first set of quarterly update sheets came out in October 1982 and 700 subscriptions by the spring of 1983 .

While the inexorable quarterly publication schedule is challenging for our relatively small department, our word processing and database programs keep the copy production and mailing work for the new 400-page cumulation on the level of a manageable chore. In the past six years one founding editor, Lois, has retired, and one moved on to another library (Elaine still does the close editing of the revised LCRI texts by mail and maintains an exacting level of accuracy). The growth in our list of subscriptions, although not as dizzying as the initial wave, has been steady, and now stands at about 1,200, including most of the major cataloging centers of the United States and Canada, as well as LCRI lovers in Europe, Africa, and Asia.

The wide acceptance of the Oberlin LCRI quarterly updating service even had us feeling a little complacent about our cozy cottage industry when a subscriber's question this spring took us aback: "Is LC taking over your publication?" This wasn't the big bad wolf; however, some very heavy hitting competition had indeed arrived on the scene. The Library of Congress Cataloging Distribution Service has, after seven years of experience in the rule interpretation field, seen fit to bring out its own version of "our" publication. At three times the cost and twice the heft of our publication, LC will still be able to use the clout of the depository system to take over some of our cottage turf. But this government/private sector competition will undoubtedly be beneficial to the faithful LCRI user. We do draw the line, however, at trying to match LC's promise to issue a 3-ring binder with its rule interpretations.

If you buy our Library of Congress Rule Interpretations for AACR2, you get to buy your own binder in your favorite color. It's the Oberlin way.

Alan Boyd and Elaine Druesedow, compilers, Library of Congress Rule Interpretations for AACR2: A Cumulation from Cataloging Service Bulletin Numbers 11-40 (Oberlin, Ohio: Oberlin College Library, 1988), ca. 400p. The cost is $\$ 24$ (additional copies $\$ 21$; price includes quarterly update sheets for CSB no.41-44). Standing orders for CSB no. 45 + accepted any time, from Alan Boyd, Oberlin College Library, Oberlin, OH 44074. 